\title{
A retrospective study of disease pattern and commonly used drugs by medical students in a tertiary care teaching hospital.
}

\author{
Ashalatha Muppur ${ }^{1}$, Anitha Nagiri ${ }^{2}$, Bharathi $\mathrm{Uppu}^{3}$ \\ ${ }_{1,2,3}$ (Assistant Professor,Dept Of Pharmacology, S.V.Medical College,Ntr University Of Health Sciences,India)
}

\begin{abstract}
:
Background: In this twenty first century the work experience of medical students has become demanding.Medical students(medicos) face long working hours and competitive work demand.Medicos like any other students suffer from maladies.

Aim: This study is to evaluate the most commonly occuring diseases and most commonly used drugs by medicos.

Methods: This is a retrospective study done on 100 medicos of various semesters(1to9)and age group 18 to 25.The study subjects were given a quesionnaire to identify diseases suffered by them and drugs used by them in the past one year.The statistical analysis of data was performed using SPSS version 17.0. pvalue was calculated using chisquare test.

Results: In this study 40 males, 60 females of age group18 to 25 years were randomly selected).Incidence of refractive errors (RE) was 75\%, infectious diseases(ID) was 50\%,psychiatry diseases(PD)was $15 \%$ and skin diseases(SD)was $15 \%$..In infectious diseases respiratory tract infections was commonest.Commonly used drugs were parcetamol(PCT) $80 \%$,cetrizine(CTZ)was $80 \%$ and ciprofloxacin was $50 \%$.

Discussion: 10 students were absolutely healthy which was insignificant( $p>0.05)$.There was significant association of age and gender in incidence of RE( $p<0.05)$.There was significant association of age and gender in the intake of ciprofloxacin( $p<0.05)$ There was no association of gender and age in the incidence of ID,PD,SD and consumption of PCT and CTZ in the medical students $(p>0.05)$.

Conclusion: The study identified, wide variety of diseases out of which RE was common,followed by ID.The commonly used drugs were PCT,CTZ and ciprofloxacin.

Keywords: Medical students, diseases, refractive errors of eye,drugs,paracetamol,ciprofloxacin
\end{abstract}

\section{Introduction}

Medical students experience specifc pressures related to their professional stage and can be at a risk of poor health.Previous research identified number of factors contribute to health of medicos ${ }^{(1)}$.These include challenging work environment,high intensity work,effort reward imbalance,home work stress and regular exposure to pain,suffering and death.Medico's enter college in their late teens(17-19)and they get the degree at the age of 24 to 30 yrs. The duration of study is four and half years and one year internship.In this journey medico's face different ailments for which they take medicines which are now moniterd by us by using a questionnaire.This study was done to examine health and drug usage experience of medical students ${ }^{(2)}$ This study collected information about health status and coping strategies employed by them.WHO defined health in broder sense in 1946 as "a state of complete physical,mental and social wellbeing and not merely absence of disease or infirmity." ${ }^{, 3)} \mathrm{A}$ disease is a particular,abnormal,pathology condition that effects part or all of an human being ${ }^{[4]}$. A drug is in broadest of terms , a chemical substance that has known biological effects on humans ${ }^{[5]}$.In this study various disease patterns and commonly used drugs by mediocs in a tertiary teaching hospital was done.

\section{Materials And Methods}

This is a retrospective ,cross sectional study conducted by dept of pharmacology ,S.V. Medical college . Medical students $(\mathrm{n}=100)$ between the ages $18-25$ were selected randomly.Students of various semesters i.e $1^{\text {st }}$ to $9^{\text {th }}$ were selected . The participants were informed about aims of the study and their verbal consent was taken . This study was done over 3 month period(march-may2014).Demographic,clinicai and medication details were collected in a specially designed proforma.The questionnaire was prepared which includes information about semester of students, gender, day scholar or hostler,diseases suffered by them in the past one year and various drugs consumed by them.Statistical analysis of data was performed using SPSS version 17.0 .Categorical measurement was presented in the form of percentages .p value is calculated for continous data through chi square test ${ }^{[6]}$.Gender and age distribution of the given data was assessed through $p$ value.p value $<0.05$ was considered stastically significant. 
A retrospective study of disease pattern and commonly used drugs by medical students in a tertiary

III. Results

A total of 100 questionnaires were distributed and collected.Out of these 40 were males and 60 were females.

TABLE-I

\begin{tabular}{|c|l|l|l|}
\hline AGEyrs & \multicolumn{1}{|c|}{ MALE } & \multicolumn{1}{|c|}{ FEMALE } & 75 \\
\hline $18-21$ & 31 & 44 & 25 \\
\hline $22-25$ & 9 & 16 & 100 \\
\hline & 40 & 60 & \\
\hline
\end{tabular}

Out of 100 students, 10 students reported to be absolutely healthy in the past one year.They reported that they haven't visited any medical care professional in the past one year.

TABLE-II Medicos suffering with ailments

\begin{tabular}{|l|l|l|l|l|}
\hline \multicolumn{1}{|c|}{ AGE yrs } & MALE & FEMALE & TOTAL & WITH OUT DISEASE \\
\hline $18-21$ & 28 & 40 & 68 & 7 \\
\hline $22-25$ & 7 & 15 & 22 & 3 \\
\hline \multicolumn{2}{|l|}{ (not significant) $^{[7]}$} & 90 & 10 \\
\hline
\end{tabular}

TABLE-III

Data showing percentage of diseases in medicos

AILMENT

PERCENTAGE

\begin{tabular}{|l|l|}
\hline NIL & 10 \\
\hline REFRACTIVE ERRORS & 75 \\
\hline INFECTIOUS DISEASES & 50 \\
\hline PSYCHIATRIC DISEASES & 15 \\
\hline SKIN DISEASES & 15 \\
\hline HYPOTHYROID & 1 \\
\hline ASTHMA & 1 \\
\hline FUNGAL INFECTION & 1 \\
\hline RHEUMATOID ARTHRITIS & 1 \\
\hline
\end{tabular}

There was overlap in the ailments suffered by medicos.20\% of students had both refractive errors and suffered from infectious diseases. Two psychiatric patients also suffered from skin problems.

Table-Iv

Types Of Infectious Diseases

$(\mathrm{N}=50)$

\begin{tabular}{|l|l|l|l|}
\hline TYPE & MALE & FEMALE & TOTAL \\
\hline RESPIRATORY TRACT INFECTIONS & 6 & 12 & 18 \\
\hline GASTROINTESTINAL INFECTIONS & 7 & 8 & 15 \\
\hline URINARY TRACT INFECTIONS & 8 & 7 & 15 \\
\hline GENITAL INFECTIONS & 1 & 1 & 2 \\
\hline
\end{tabular}

Table-V

Data Showing Percentage Of Commonly Used Drugs Taken By Medicos DRUGS

\begin{tabular}{|l|l|}
\hline PARACETAMOL & 80 \\
\hline CETRIZINE & 80 \\
\hline CIPROFLOXACIN & 50 \\
\hline B COMPLEX & 40 \\
\hline PANTOPRAZOLE & 15 \\
\hline ANTI TUSSIVES & 10 \\
\hline DOXYCYCLINE & 5 \\
\hline FLUOXETINE & \\
\hline KETOCONOZOLE & 5 \\
\hline ALBEDNAZOLE & 1 \\
\hline BENZYL BENZOATE & 1 \\
\hline SALBUTAMOL & \\
\hline HYDROXY CHLOROQUINE & \\
\hline & 1 \\
\hline
\end{tabular}


Table-Vi

Age And Gender Distribution Of Diseases In Medical Students

Refractive Errors $(\mathrm{N}=75)$

\begin{tabular}{|l|l|l|l|l|}
\hline AGE yrs & MALE & FEMALE & TOTAL & WITHOUT REFRACTIVE ERROR \\
\hline $18-21$ & 18 & 32 & 50 & 25 \\
\hline $22-25$ & 7 & 18 & 25 & 0 \\
$\mathrm{X}^{2}=11.111, \mathrm{p}=0.000858$ & (significant)
\end{tabular}

INFECTIOUS DISEASES $(\mathrm{n}=50)$
\begin{tabular}{|l|l|l|l|l|}
\hline AGE yrs & MALE & FEMALE & TOTAL & $\begin{array}{l}\text { WITHOUT INFECTIOUS } \\
\text { DISEASES }\end{array}$ \\
\hline $18-21$ & 13 & 22 & 35 & 45 \\
\hline $22-25$ & 6 & 9 & 15 & 5 \\
$X^{2}=1.333, p=0.24$ & (non significant)
\end{tabular}

PSYCHIATRIC DISEASES $\quad(\mathrm{n}=15)$

\begin{tabular}{|l|l|l|l|l|}
\hline AGE yrs & MALE & FEMALE & TOTAL & $\begin{array}{l}\text { WITHOUT PSYCHIATRIC } \\
\text { DISEASES }\end{array}$ \\
\hline $18-21$ & 3 & 8 & 11 & 64 \\
\hline $22-25$ & 2 & 2 & 4 & 21 \\
$\mathrm{X}^{2}=0.0261, \mathrm{p}=0.871 \quad$ (non significant)
\end{tabular}

SKIN DISEASES $(\mathrm{n}=15)$

\begin{tabular}{|l|l|l|l|l|}
\hline AGE yrs & MALE & FEMALE & TOTAL & WITHOUT SKIN DISEASES \\
\hline $18-21$ & 4 & 5 & 9 & 66 \\
\hline $22-25$ & 3 & 3 & 6 & 19 \\
\hline $\mathrm{X}^{2}=2.1176, \mathrm{p}=0.14 \quad$ (non significant)
\end{tabular}

Table-Vii

Age And Gender Distribution Of Drugs Commonly Used By Medical Students

\begin{tabular}{l} 
Paracetamol Usage $(\mathrm{N}=80)$ \\
\begin{tabular}{|l|l|l|l|l|}
\hline AGE yrs & MALE & FEMALE & TOTAL & NOT USED \\
\hline $18-21$ & 26 & 44 & 70 & 15 \\
\hline $22-25$ & 3 & 7 & 10 & 5 \\
$X^{2}=3.7037, p=0.054$ & (non significant)
\end{tabular} \\
\hline
\end{tabular}

CETRIZINE USAGE $\quad(\mathrm{n}=80)$

\begin{tabular}{|l|l|l|l|l|}
\hline AGE yrs & MALE & FEMALE & TOTAL & NOT USED \\
\hline $18-21$ & 28 & 30 & 58 & 17 \\
\hline $22-25$ & 11 & 11 & 22 & 3 \\
\hline
\end{tabular}

\section{CIPROFLOXACIN USAGE $(\mathrm{n}=50)$}

\begin{tabular}{|l|l|l|l|l|}
\hline AGE yrs & MALE & FEMALE & TOTAL & NOT USED \\
\hline $18-21$ & 20 & 12 & 32 & 43 \\
\hline $22-25$ & 8 & 10 & 18 & 7 \\
\hline
\end{tabular}

\section{Discussion}

In our study, females were sixty and males were forty $(n=100)$.Students in the age group 18-21 were 75 and students in the age group 22-25 were 25 (TABLE-I).Ten students reported absolute health in the past one year $\quad(\mathrm{p}>0.05$ non significant)(TABLE-II). $75 \%$ of students suffered from refractive errors and wore spectacles. $50 \%$ of the students suffered from infectious diseases, $15 \%$ from psychiatric diseases and $15 \%$ from skin diseases(TABLE III).In refractive errors maximum cases suffered from myopia ${ }^{[8]}$.In infectious diseases, the incidence of respiratory tract infections was more than gastrointestinal, urinary tract and genital infections(TABLE-IV).Among psychiatric disease depression was most common followed by anxiety disorders. Among skin diseases acne ${ }^{[9]}$ was most common. Two cases of scabies ${ }^{[10]}$ was observed. There was a sporadic case of hypothyroidism, asthma, fungal infection and rheumatoid arthritis(TABLE III).

According to this study the most popular drug consumed by students is paracetamol (80\%) followed by cetrizine $(80 \%)$.Among the antibiotics ciprofloxacin was commonly used.B Complex, pantoprazole, anti tussives, doxycycline, fluoxetine were other commonly used drugs. There was sporadic usage of drugs like ketaconozole, benzyl benzoate, salbutamol and hydroxyl chloroquine(TABLE-V). 
TABLE -VI shows Age and Gender distribution of diseases in medical students. There is significant association of refractive errors with age and gender $(\mathrm{p}<0.05)$. There is insignificant association with age and gender in the incidence of infectious diseases, psychiatric diseases and skin diseases. TABLE- VII depicts age and gender distribution of commonly used drugs in medical students. There is insignificant association with paracetamol and cetrizine usage $(\mathrm{p}>0.05)$. There is significant association with age and gender in ciprofloxacin usage.

Disease patterns vary with occupation. A medical student to get a undergraduate degree ${ }^{[11]}$ has to read minimum of twentyfive books covering thirteen subjects. As eye is most used organ he/she suffers from refractive errors.High incidence of usage of paracetamol is attributed to headache which could be due to stress $^{[12]}$ during the tenure of medical education. This study compared the incidence of diseases ${ }^{[13]}$ like ID,PD and SD.It also compares the usage of commonly used drugs like cetrizine and ciprofloxacin ${ }^{[14]}$.

\section{Conclusion}

The diseases in medical students was diverse and heterogenous, out of which refractive errors of eye was common. Drugs used also showed disparity, out of which paracetamol was commonly used.

\section{Acknowledgment}

We sincerely thank Dr Vasundhara Devi HOD(department of pharmacology) for her guidance.

\section{References}

[1]. General Medical Council (2009) Tomorrow's Doctors London, GMC, paragraphs 124 and 126

[2]. Dyrbye LN, Thomas MR, Shanafelt TD (2006) Systematic review of depression, anxiety, and other indicators of psychological distress among U.S. and Canadian medical students Acad Med 81(4): 354-73

[3]. Sport, Disability and an Original Definition of Health. Zenit.org (February 27, 2013).

[4]. McWhinney IR (April 1987). "Health and disease: problems of definition". CMAJ 136 (8): 815. PMC 1492121. PMID 3567791

[5]. "Drug." Dictionary.com Unabridged (v 1.1), Random House, Inc., via dictionary.com. Retrieved on 20 September 2007.

[6]. Weisstein, Eric W., Test.html "Chi-Square Test", MathWorld.

[7]. Yates, F (1934). "Contingency table involving small numbers and the $\chi^{2}$ test". Supplement to the Journal of the Royal Statistical Society 1(2): 217-235.JSTOR 2983604

[8]. Etiopathogenesis and management of high-degree myopia. Part I

[9]. Thappa, Devindermohan; Adityan, Balaji; Kumari, Rashmi (2009). "Scoring systems in acne vulgaris". Indian Journal of Dermatology, Venereology and Leprology 75 (3): 323 - doi:10.4103/0378-6323.51258. PMID 19439902

[10]. Walton, SF; Currie, BJ (April 2007). "Problems in Diagnosing Scabies, a Global Disease in Human and Animal Populations".Clinical Microbiology Reviews 20 (2): 268-79. doi:10.1128/CMR.00042-06. PMC 1865595. PMID 17428886.

[11]. http://mciindia.org/InformationDesk/MedicalCollegeHospitals/ListofCollegesTeachingMBBS.aspx

[12]. Hillis J, Morrison S, Alberici F, Reinholz F, Shun M, Jenkins K (2012) 'Care Factor': Engaging medical students with their wellbeing Med Educ46(5): 509-10

[13]. "Regents Prep: Living Environment: Homeostasis". Oswego City School District Regents Exam Prep Center. Retrieved 2012-1112.

[14]. Laurence Brunton; John Lazo; Keith Parker (23 August 2005).Goodman \& Gilman's The Pharmacological Basis of Therapeutics. McGraw-Hill Prof Med/Tech. ISBN 978-0-07-142280-2. Retrieved 30 October 2012. 